\title{
Biological determinants of phase angle among Brazilian elite athletes
}

\author{
Alexandre G. Torres ${ }^{1}$, Karla J. F. Oliveira ${ }^{1}$, Astrogildo V. Oliveira-Junior ${ }^{2}$, Mariana C. Gonçalves ${ }^{2}$ \\ and Josely C. Koury ${ }^{2}$ \\ ${ }^{1}$ Laboratório de Bioquímica Nutricional e de Alimentos, Instituto de Química, Universidade Federal do Rio de Janeiro, \\ Rio de Janeiro, Brazil and ${ }^{2}$ Instituto de Nutrição, Universidade do Estado do Rio de Janeiro, Rio de Janeiro, Brazil
}

Intense physical training may affect cellular membrane stability. Phase angle (PA) is a non-invasive measure related to cellular membrane composition and stability that is calculated from resistance and reactance and is obtained by bioelectrical impedance (BIA) ${ }^{(1)}$. Previous reports have shown that PA is associated to age, gender and $\mathrm{BMI}^{(2)}$ but little is known about the sources of variation in PA among athletes. The aim of the present study was to investigate the determinants of PA in male elite athletes ( $\geq 3 \mathrm{~h}$ training daily, and participation in international competition). Healthy athletes ( $n$ 158; age $13-48$ years) who participated in this cross-sectional observational study practiced the following specialist sports: adventure running, $n 6$; cycling, $n 11$; judo, $n$ 7; long-distance running, $n$ 27; short-distance running, $n 14$; soccer, $n$ 50; swimming, $n 13$; triathlon, $n 15$; water polo, $n 15$. BIA was performed using a BIA 101-Q impedance analyser (RJL Systems, MI, USA) under a strict standardized procedure ${ }^{(2)}$. The BIA measurements were routinely carried out at 08.00 hours after $\geq 8 \mathrm{~h}$ fast and $16 \mathrm{~h}$ rest. All the subjects were of normal BMI and hydration status. The athletes were stratified according to age ${ }^{(2)}$ and the data for PA, weight, height and BMI are presented in the Table.

\begin{tabular}{|c|c|c|c|c|c|c|c|c|c|}
\hline \multirow[b]{2}{*}{ Age subgroup (years) } & \multirow[b]{2}{*}{$n$} & \multicolumn{2}{|c|}{$\mathrm{PA}\left({ }^{\circ}\right)$} & \multicolumn{2}{|c|}{ Weight $(\mathrm{kg})$} & \multicolumn{2}{|c|}{ Height $(\mathrm{m})$} & \multicolumn{2}{|c|}{ BMI $\left(\mathrm{kg} / \mathrm{m}^{2}\right)$} \\
\hline & & Mean & $\overline{\mathrm{SD}}$ & Mean & SD & Mean & $\overline{\mathrm{SD}}$ & Mean & $\mathrm{SD}$ \\
\hline $10-19$ & 79 & $6.89^{\mathrm{a}}$ & 1.02 & $56.2^{\mathrm{a}}$ & 13.9 & $1.67^{\mathrm{a}}$ & 0.12 & $19.8^{\mathrm{a}}$ & 2.70 \\
\hline $20-29$ & 50 & $8.14^{\mathrm{b}}$ & 0.68 & $73.3^{\mathrm{b}}$ & 11.8 & $1.77^{\mathrm{b}}$ & 0.07 & $23.4^{\mathrm{b}}$ & 2.57 \\
\hline $30-39$ & 22 & $7.78^{\mathrm{a}, \mathrm{b}}$ & 0.68 & $73.8^{\mathrm{b}}$ & 10.7 & $1.79^{\mathrm{b}}$ & 0.07 & $23.0^{\mathrm{b}}$ & 2.70 \\
\hline $40-49$ & 7 & $7.47^{\mathrm{a}, \mathrm{b}}$ & 0.39 & $70.5^{\mathrm{b}}$ & 7.8 & $1.72^{\mathrm{a}, \mathrm{b}}$ & 0.09 & $23.8^{\mathrm{b}}$ & 1.93 \\
\hline
\end{tabular}

${ }^{\mathrm{a}, \mathrm{b}}$ Means with unlike superscript letters in the same column were significantly different (ANOVA with Tukey's post-hoc test; $P<0.005)$. The effect of age on PA was independent of BMl and sport specialism (MANOVA).

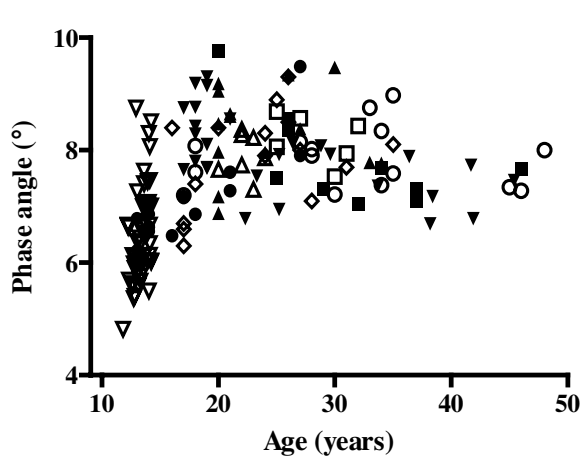

口 Adventure running

- Cycling

$\Delta$ Judo

v Long-distance running

- Short-distance running

$\nabla$ Soccer

- Swimming

- Triathlon

$\diamond$ Water-polo

Figure. Association between PA and age for all athletes.

In agreement with previous findings ${ }^{(2)} \mathrm{PA}$ was positively correlated with BMI $(r 0.66 ; P<0.001)$. In contrast to previous reports ${ }^{(2)} \mathrm{PA}$ was lower in adolescents than in young adults (Table), and increased steeply with age within the same specialty (soccer; Figure). Among athletes aged 10-19 years $57 \%$ of PA values were lower than the 5 th percentile of a reference group ${ }^{(2)}$, in contrast to the other three age subgroups, for whom the corresponding values were $2 \%, 0 \%$ and $0 \%$, respectively. The results suggest that the intense physical training, which is usual for elite athletes, may negatively influence PA of male adolescents, which might be related to cellular membrane stability.

Supported by CNPq, CAPES and FAPERJ (Brasil). K. J. F. O. was a recipient of a CAPES studentship.

1. VanderJagt DJ, Huang YS, Chuang LT et al. (2002) Arch Dis Child 87, 252-254.

2. Barbosa-Silva MCG, Barros AJD, Wang J et al. (2005) Am J Clin Nutr 82, 49-52. 